\title{
The Pedagogical Application of the Grammar Translation Method as an Effective Instructional Methodology in Teaching English as a Second Language
}

\author{
K. G. Swarnananda Gamage \\ English Language Teaching Department, Buddhist and Pali University of Sri Lanka, Homagama, Sri Lanka \\ Email: swarnananda@bpu.ac.lk
}

How to cite this paper: Swarnananda Gamage, K.G. (2020) The Pedagogical Application of the Grammar Translation Method as an Effective Instructional Methodology in Teaching English as a Second Language. Open Access Library Journal, 7: e6913.

https://doi.org/10.4236/oalib.1106913

Received: October 20, 2020

Accepted: November 8, 2020

Published: November 11, 2020

Copyright $\odot 2020$ by author(s) and Open Access Library Inc.

This work is licensed under the Creative Commons Attribution International License (CC BY 4.0).

http://creativecommons.org/licenses/by/4.0/

\section{(c) (i) Open Access}

\begin{abstract}
This article primarily investigates the effectiveness of the Grammar Translation Method (GTM), one of the most traditional methods in the pedagogical application of teaching English as a second language (L2). Despite being traditional, GTM is being widely used in L2 instructional settings, particularly at tertiary level education. Though there is no conclusive evidence to suggest that GTM was initially based on specific theoretical framework, its predominant techniques including translation and memorization still play a crucial role in second language teaching process. The current study, a part of an action research, was conducted at Buddhist and Pali University of Sri Lanka with a sample of sixty students selected purposively, who were exposed to selected techniques of GTM pedagogy. This qualitative study employed a pre-test post-test quasi-experimental research design. A paired-sample t-test was used to compare the mean value difference: significant $\mathrm{p}$-value ( $\mathrm{p}<$ 0.005) indicates the efficacy of GTM in the pedagogical application. These results suggest that vital techniques of GTM can be effectively incorporated into current pedagogical practices to maximize the learning outcomes.
\end{abstract}

\section{Subject Areas \\ English Language Teaching}

\section{Keywords}

Grammar Translation Method, Second Language, Translation, Memorization, Pedagogy 


\section{Introduction}

Second Language Acquisition (SLA) can broadly be defined as the internalization of language rules and formulas which are used to communicate in any language other than a learner's native language or mother tongue. Simply, Second Language Acquisition is the learning of any language, provided only that the leaning of this language takes place sometime later than the acquisition of the first language, an individual's home language (Brooks 1964 [1], Littlewood 1984 [2], Krashen, 1985 [3], Gass \& Schachter, 1989 [4]).

English as a Second Language is also taught at tertiary level education such as in technical colleagues and universities, often as a compulsory subject. For instance, at the university level, English language learning is a compulsory requirement for undergraduates to obtain their degrees. Within the school curriculum, the teaching methodology is usually decided and recommended at the national level, by the respective authorities affiliated to the Ministry of Education or the National Institute of Education, Sri Lanka. However, such recommendations often vary in line with the research experiments and hypotheses on SLA, conducted in non-local SLA contexts. For instance, during the late 1960s until the early 1970s, a teaching methodology called Structural approach ${ }^{1}$ which is quite similar to Grammar Translation Method was used in the Sri Lankan school system; the focus was shifted to Communicative Language Teaching since the late 1970s. In other words, for decades, English language teaching in Sri Lanka has been greatly influenced by traditional teaching method, such as the Grammar Translation Method, the Audio-Lingual Method and the Communicative Language Teaching Method.

Mastering a language is related to one's cognitive context which is undoubtedly influenced by his/her culture and personality; this is particularly so in relation to Second Language teaching/learning contexts. Thus, it was speculative whether the methodologies derived from the psycholinguistic theories posited through the findings based on non-Asian contexts would be equally applicable in non-western contexts as well.

\section{Literature Review}

The Grammar Translation method was originally employed to teach classical languages like Greek and Latin, therefore eventually called Classical Method. The Grammar Translation method was initially used for the purpose of helping students read and appreciate literature written in foreign languages. It was also hoped that, through the study of the grammar of the target language, students would gain a better understanding of the grammar of their native language and that this familiarity would help them speak and write their native language better. Further, it was thought that forging language learning would help students

${ }^{1}$ Structural approach is a scientific study of the fundamental structures of English language, their analysis and logical arrangement. The structural approach is based on the belief that in the learning of a foreign language, mastery of structures is more important than acquisition of vocabulary. 
to develop their intellect; it was recognized that even though students would never use the target language, the mental exercise of learning would be beneficial (Diane Larsen-Freeman, 2000) [5].

Language teaching has a long history although it has just emerged into its own as a profession only in the 20th century. A glance back in history reveals the existence of few research-based language teaching methods prior to the 20th century. "Foreign" or "second" language learning in schools in those days was synonymous to the learning of Latin or Greek languages. During the 16th century, the teaching of "Latin" as a promoter of intellectuality through "mental gymnastics" became an indispensable subject matter of learning and teaching in higher education. "Latin" was taught in grammar schools through rote learning of grammar rules, rhetoric memorization of vocabulary and of declensions and conjugations, translation of texts, doing written exercises like writing sample sentences, parallel texts and dialogues. Latin language teaching was mainly based on the classical method (Diane Larsen-Freeman, 2000) [5].

With the emergence of classical method as the pioneering method to learn and teach Latin, more languages began to be taught in educational institutions in the eighteenth and nineteenth centuries in the similar trend of teaching Latin as the textbook consisted of statements of abstract grammar rules, lists of vocabulary and sentences for translation. Later in the late 19th century, this classical method to teach classical Latin and Greek language (Chastain, 1988 as cited in Freeman \& Lynne, C2008, p.11) [6] came to be known as Grammar Translation Method (Grammar Translation). Since then, Grammar Translation remained as a pioneering standard methodology for foreign language teaching. This method dominated European and Foreign language teaching from the 1840s to the 1940s (Diane Larsen-Freeman, 2000) [5].

Theory of language learning has an utmost relevance with the psycholinguistic and the cognitive process involved in language learning and with the conditions that allow for successful use of these processes. However, there is no sufficient evidence in existing literature to suggest that the Grammar Translation Method was initially based on any recognized theoretical framework. Nevertheless, Grammar Translation method which concentrates on translation of literary texts from native language to target and vice-versa focuses on grammar rules and vocabulary lists, while it follows deductive approach as a theory of language learning. The learner accordingly uses his/her cognitive faculty to memorize grammatical rules and vocabulary lists for translation and reading comprehension. Learning grammar rules and vocabulary through memorization is central to language learning according to theory of language learning in Grammar Translation method. Such memorization of language elements and translation can be viewed as modification of learner behaviour: thus one could argue that the elements of behaviourism could be noticed in Grammar Translation method (Richards \& Rodgrers, 2001) [7]. The principles of deductive learning used in this method reflect advanced pedagogical focus. Language was primarily meant for 
reading and writing rather than listening and speaking according to theoretical views of language learning of Grammar Translation method.

\section{Methodology}

The current study aimed at the practical improvement in language teaching and learning at classes at Buddhist and Pali University (BPU). It also involved understanding of the pedagogical issues at BPU and to form an intervention strategy for better learning outcomes. To achieve these objectives, the research objectives are put forward at three main stages:

- To understand the teaching practice at BPU through a quantitative analysis of students' performances in language learning.

- To form an intervention strategy in the light of the exploration and implement it in classrooms.

- To evaluate implementation through a quantitative and qualitative approach. Approaching these objectives required implementing and managing change through the research process. The change, due to teachers' practice, can include many things like teaching practice, self-awareness, knowledge, beliefs, attitudes, and understanding (Bailey, 1992 [8]; Jackson 1992 [9]). Therefore, the choice of research method had to be based on a framework that can fulfill these requirements. Moreover, the research was based on the educational context, which included the analysis of existing teaching methodologies (English as a second language) and forming an action that can transform and improve pedagogies. Therefore, an action research was an applicable approach for this kind of research as Corey's (1953, as cited in Noffke 1997, p. 316-317) [10] definition of action research states that action research is employed by "educational practitioners because they assume that by doing so they can make better decisions and engage in better actions". In action research, the important phases could be found-intervene, investigate and improve. It is an intervention to the Compulsory English Language Course conducted for the first year students in Buddhist and Pali University of Sri Lanka and an investigation of prevailing techniques employed in the process of teaching English as a second language. The objective was to improve the prevailing pedagogical process applied in the instructions.

\section{Learners:}

Sixty male second year undergraduates ${ }^{2}$ of the BPU Sri Lanka were taken as participants with a purposive sample which is also known as judgmental, selective or subjective sampling. It is very useful to describe the major impact on a larger population. It is an extremely handy sampling technique through which a researcher is able to judge when choosing the members of population to participate in the study. Accordingly, 60 students who could correspond to the objectiveness of our study, and those who have an interest in our study and willingness to participate in the research were chosen. All of them had scored between

${ }^{2}$ It is commonly hypothesized that SLA is affected by individual learner factors such as age, gender, personality and similar factors. Hence, as learner participants from BPU were confined to males, the issue of gender variability in language learning is already controlled. 
40 - 60 marks on a language test conducted by the university, prior to the research. They were between the ages of 23 - 24 years. Participant students of this study were from a similar linguistic background: their mother tongue was Sinhala ${ }^{3}$; they had started learning English as a Second Language at the age of 10 years, at state-run educational institutes (either schools or pirivenas ${ }^{4}$ ) situated in Sri Lanka; these students had learned English at such institutes for 10 years, as English is a compulsory requirement. A majority of the students admitted that they had obtained Simple Passes ${ }^{5}$ for English Language at the General Certificate of Education (Ordinary Level) Examination administered by the Ministry of Education of the country. After enrolling at university, they had followed the ESL non-credit course offered by the university. However, even though English is a compulsory requirement to obtain the degree, these students had not followed it regularly due to various personal reasons. During the period of this research study, the subjects did not follow any English Language courses except for the classes conducted for the purpose of this study. During this period, they also followed the three subjects for the degree which were taken in the Sinhala medium. These undergraduates were supposed to follow lectures for three subjects related to their degree in their L1-Sinhala. Thus, their exposure to English language during the research was limited.

The study created a learner group which was selected purposively from the second year students as mentioned above. Yet, as the research questions refer to them, the learner group is named and defined below for better comprehension.

- C-GTM group = The group of students of BPU who were exposed only to Grammar Translation Method during a specified period of the study

- Hypothesis 1

- Is there a correlation between pre and posttest marks of C-GTM group?

\section{Analysis and Discussion}

\section{Rationale of Analysis}

The main hypothesis being tested in each component of the study was whether each the teaching methodology, as practiced through a number of inherent techniques, had a positive effect on the English language proficiency of the selected sample of second language learners. The main hypothesis was tested in the study, the details of which have been illustrated in section below in this discussion.

\footnotetext{
${ }^{3}$ Sinhala is a national language of Sri Lanka and it is the first language of the majority of Sri Lankans: Tamil is the other national language.

${ }^{4}$ Although a Pirivena originally means a monastic college for the education of Buddhist priests in Sri Lanka, these have been the centers of secondary and higher education for some lay people as well, and due to socio-cultural changes such institutes are not isolated, but integrated into the dynamics in society.

${ }^{5}$ A student can obtain a Simple Pass, if s/he scores approximately 30 - 40 marks (out of 100) for the ESL test paper: students sit for this General Certificate of Education (Ordinary Level) examination, after learning ESL for 08 years at school: they are between the ages of 15 - 16 years during this time. The aim of the test is to evaluate students' knowledge in grammar, vocabulary, reading and writing skills.
} 
In order to exclude all the confounds and control the variables that may have impacted on the teaching effects, the t-test was used to ensure study groups that did not have any significant difference in terms of English proficiency level at the beginning of the study. All the final scores of pretest were converted to be valid to perform the statistical analysis. Thus they were recorded and fed into SPSS. After the instructional intervention, all the participants were tested again. All of the scores were subsequently rerecorded and calculated.

In a nut shell, the entire analysis was focused on a paired t-test to statistically measure the efficacy of the selected teaching methodology. Conventionally, t-test is used to compare two populations that means where there are two samples in which observations in one sample can be paired with observations in the other sample. Under the null hypothesis, this statistic follows a t-distribution with $\mathrm{n}-1$ degrees of freedom. In this study, before and after conducting instructional sessions, students' English proficiency scores were tested using a paired t-test. The logic of using a paired t-test is illustrated below:

The study was based on the following general hypotheses:

$H_{0}$ : There is no mean difference on test score after the instructional intervention.

$H_{1}$ : There is a mean difference on test score after the instructional intervention.

To test the null hypothesis that the true mean difference is zero, the procedure is as follows: if

$x=$ test score before the instructional intervention

$y=$ test score after the instructional intervention

Following formulae were used in calculating the statistics of the t-test:

1) Calculating the difference between the two observations on each pair: $\left(d_{i}=x_{i}-y_{i}\right)$.

2) Calculating the mean difference:

$$
\bar{d}=\frac{\sum d_{i}}{\sum n}
$$

3) Calculating the standard deviation of the differences, SD, and Standard Error of the mean difference

$$
S E(\bar{d})=\frac{S d}{\sqrt{n}}
$$

4) Calculating the t-statistic

$$
T=\frac{\bar{d}}{S E(\bar{d})}
$$

5) Using the tables of the t-distribution to compare value for $T$ to the tn -1 distribution. (This will give the $\mathrm{p}$-value for the paired $\mathrm{t}$-test.)

If $\mathrm{t}$-value $>$ table value or $\mathrm{p}$-value $<\alpha$, there is sufficient evidence to reject $H_{0}$ at selected confidence level. 
Confidence interval would be useful to calculate a confidence interval for the mean difference to identify within what limits the true difference is likely to lie.

A 95\% confidence interval for the true mean difference is:

$$
\bar{d} \mp t^{*} \times S E(\bar{d}) \text { Or equivalently } \bar{d} \mp t^{*} \times \frac{S d}{\sqrt{n}}
$$

The participants of this study involved 60 undergraduates studying in the second year of BA course in Buddhist and Pali University. The average age of the students was 22.5 years and their mother tongue was Sinhala.

One main instrument utilized in this study was a pretest which was administered to the selected subjects to determine the students' prior status of English language proficiency. It consisted of 35 objective test items. The total score was 50 points distributed among these items. At the beginning of the test paper, the instructions of the test were introduced. The time allocated for the test was (02) hours. The pretest reliability was found to be (0.94), which was considered to be extremely satisfactory for the purpose of this study. After the treatment, a post test was administered to assess the efficacy of the GTM. The posttest was identical to the pretest as it had the same type of items, number, and structure.

The test content was validated by two experts in the field of linguistics. Considering the test instructions, the relevance of questions to content, its suitability to the research goals and objectives, the number and arrangement of questions, and the appropriacy of the time assigned for the test, the team was asked to validate the content of the test.

Efficacy of Grammar Translation method on C-GT group's language proficiency.

Before and after the Pedagogical application of GTM the pretest and posttest were conducted to collect data which is statistically analyzed to denote the efficacy of GTM in second language proficiency. The hypothesis described in the methodology was tested with the statistics collected from the pretest and posttest of GTM.

According to Table 1 the mean of pretest scores of the study group was 32.87, while the mean of posttest scores of the group was 37.33, It seems that grammar translation based learning has a greater effect on students' English language proficiency, though so much criticism leveled against its techniques and pedagogical process. (Correlation coefficient of the pretest and posttest in the study group was 0.635).

In order to explore statistically the efficacy of Grammar Translation method on GT group's language proficiency, the hypotheses illustrated in Methodology Chapter were tested.

Table 1. Descriptive statistics of the pretest and posttest scores.

\begin{tabular}{ccccccc}
\hline & $\mathrm{N}$ & Mean & Std. Error & Std. Devi & Minimum & Maximum \\
\hline Pretest & 60 & 32.87 & 2.164 & 8.383 & 18 & 48 \\
Posttest & 60 & 37.33 & 2.095 & 8.112 & 23 & 48
\end{tabular}


According to Table 2 and based on the probability of the obtained significance level ( $\mathrm{p}$-value $=0.000$ ), and also comparison of it with the significance level $\alpha=0.01$, as the probability of significance level of the test was less than $\alpha=0.01$ (i.e. p-value $=0.000<\alpha=0.01$ ), the equivalence between the mean scores of pretest and posttest was strongly rejected.

While Figure 1 demonstrates the mean value difference, Figure 2 provides the dispersion of the GTM group, providing evidence of the significant improvement shown from pretest to posttest. Although the development of mean value indicates the overall increase of almost four marks, the dispersion suggests that the students who perform at average level at the pretest (this includes majority of the group) haven't performed an equal level of competence at the posttest. They have, in fact performed worse compared to the pretest. A few students who have already performed well at the pretest have performed exceedingly well at the post test, which has largely contributed to the significant improvement of the mean difference from pretest to post test. Some participants who performed not so well at the pretest too have improved a little. However, as noted before, the majority of the group doesn't seem to contribute to the significant increase shown in the mean value difference.

Table 2. Paired T-Test results for the marks of C-GT group.

\begin{tabular}{|c|c|c|c|c|c|c|}
\hline \multicolumn{2}{|c|}{ Paired Differences } & \multirow{2}{*}{\multicolumn{2}{|c|}{$\begin{array}{l}\text { 95\% Confidence Interval of the } \\
\text { Difference }\end{array}$}} & \multirow{3}{*}{ T-Value } & \multirow{3}{*}{ Df } & \multirow{3}{*}{ Sig. } \\
\hline \multirow{2}{*}{ Mean } & \multirow{2}{*}{$\begin{array}{c}\text { Std. } \\
\text { Deviation }\end{array}$} & & & & & \\
\hline & & Lower & Upper & & & \\
\hline 4.467 & 3.642 & 2.450 & 6.484 & 4.750 & 14 & 0.000 \\
\hline
\end{tabular}

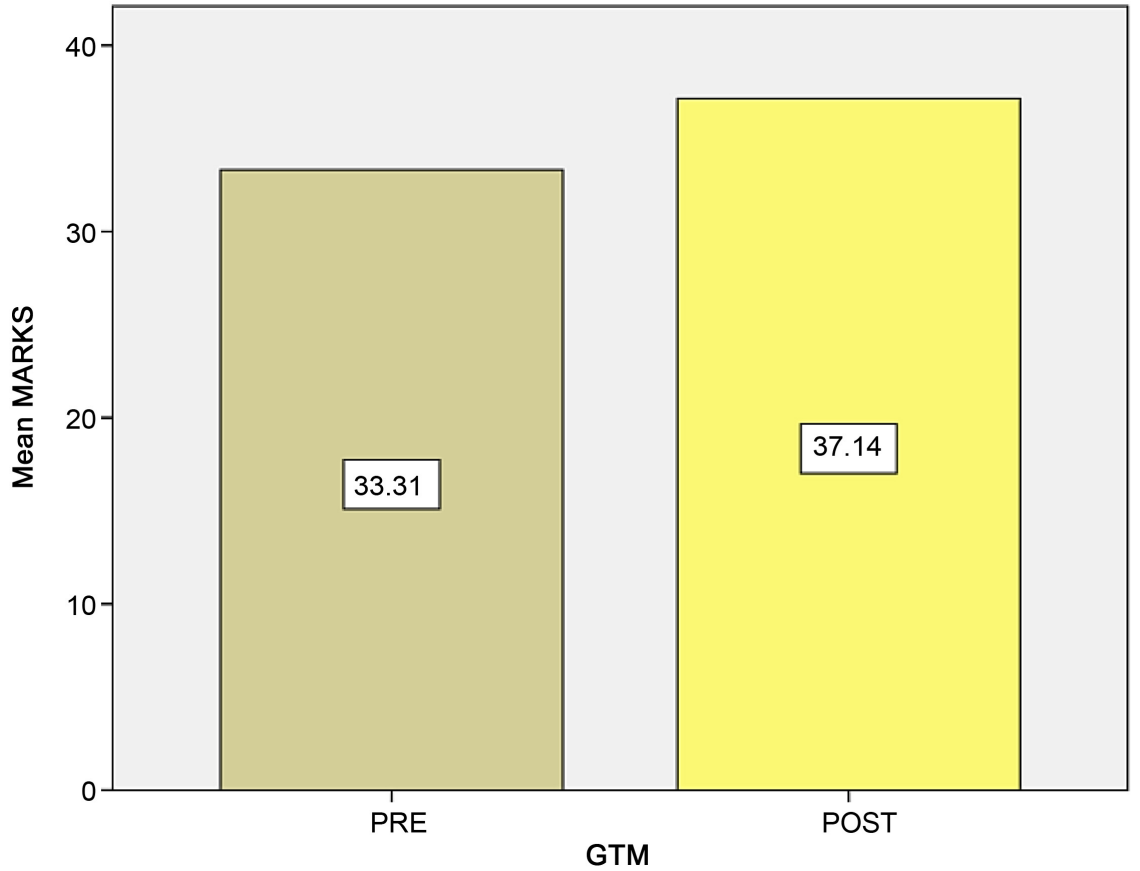

Figure 1. The mean values of grammar translation methods. 


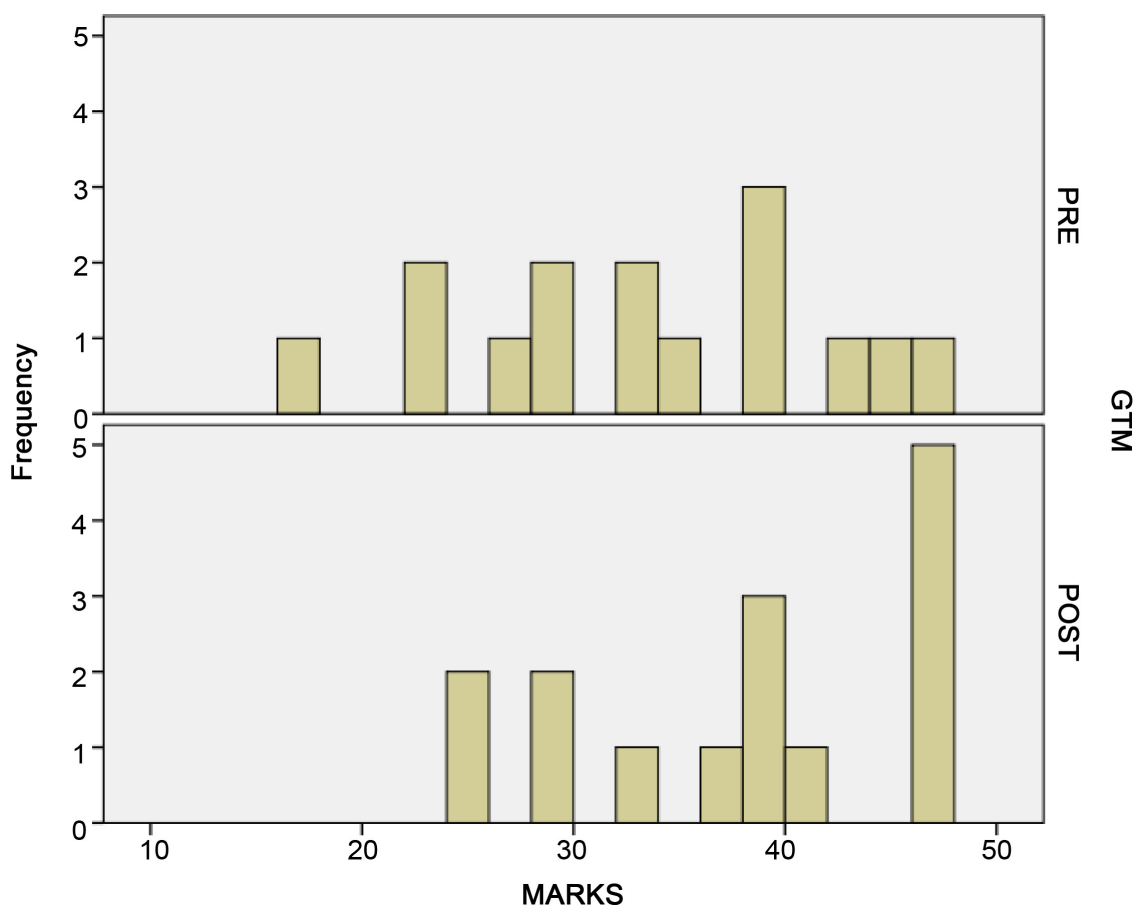

Figure 2. The dispersion: grammar translation method.

\section{Conclusions}

Thus we can arrive at a conclusion that though there is significant mean value improvement, it is difficult to prove that the majority of the participants have been able to improve by the pedagogical application applied through the Grammar Translation Method. These results suggest the need to incorporate some of the techniques of Grammar Translation method into more comprehensive new approaches for: Grammar Translation method has helped learners to develop their language proficiency. Most probably, the techniques like translation and memorization had had considerable positive effect on teaching learning process when compared to the techniques of other relatively new methods. The deductive application in grammar teaching in this case too seems to have contributed to developing grammatical competence among students. However, the learning of second languages, like any educational undertaking, is subject to such a complexity of influences that the strategies of research cannot afford to confine themselves merely to those inquiry procedures that precedent alone has sanctioned. Yet, this innovative research, carried out from the perspectives of instructional strategies and pedagogical activities, has shed much light on the complexities of second language development. However, this study was confined to Buddhist and Pali University, and the efficacy of a teaching method such as Grammar Translation Method cannot be effectively measured by limiting the study sample drawn from a single institution.

One of the main limitations associated with this study is based on the fact that it is a study conducted at one selected institute and the conclusions found based on the research cannot be extended more generally. In fact, the study was con- 
fined to one university, Buddhist and Pali University and to one teacher as the practitioner. Therefore, making firm generalizations based on this limited context may be controversial. Further, the efficacy of a teaching method such as Grammar Translation Method cannot be effectively measured by limiting the study sample drawn from a single institution.

\section{Conflicts of Interest}

The author declares no conflicts of interest regarding the publication of this paper.

\section{References}

[1] Brooks, N. (1964) Language and Language Learning. 2nd Edition, Harcourt, Brace, and World, New York.

[2] Littlewood, W. (1984) Foreign and Second Language Learning: Language Acquisition Research and Its Implications for the Classroom. Cambridge University Press, Cambridge.

[3] Krashen, S.D. (1985) The Input Hypothesis: Issues and Implications. Longman, New York.

[4] Gass, S. and Schachter, J. (1989) Linguistic Perspectives on Second Language Acquisition. Cambridge University Press, Cambridge. https://doi.org/10.1017/CBO9781139524544

[5] Larsen-Freeman, D. (2000) Techniques and Principles in Language Teaching. 2nd Edition, Oxford University Press, India.

[6] Larsen-Freeman, D. and Lynne, C. (2008) Complex Systems and Applied Linguistics Oxford Applied Linguistics. Oxford University Press, Oxford.

[7] Richards, J.C. and Rodgers, T.S., Eds. (2001) Approaches and Methods in Language Teaching. Cambridge University Press, Cambridge.

[8] Bailey, K.M. (1992) The Processes of Innovation in Language Teacher Development: What, Why and How Teachers Change. In: Flowerdew, J., Brock, M. and Hsia, S., Eds., Perspectives on Second Language Teacher Education, City Polytechnic of Hong Kong, Hong Kong, 253-282.

[9] Jackson, P.W. (1992) Helping Teachers Develop. In: Hargreaves, A. and Fullan, M.G., Eds., Understanding Teacher Development, Teachers College Press, New York.

[10] Noffke, S.E. (1997) Professional, Personal, and Political Dimensions of Action Research. Review of Research in Education, 22, 305-343.

https://doi.org/10.2307/1167378 